\title{
Justicia agraria y conflictos de tierras en Colombia durante la primera mitad del siglo XX. El caso de Santander*
}

Artículo recibido: 13-04-2016/ Artículo modificado: 24-6-2016/Artículo aceptado: 5-7-2016

\section{Elisa Martín Peré}

Licenciada en Derecho de la Universidad de Granada (España). Magíster en Historia de la Universidad Industrial de Santander (Colombia). Diploma de Estudios Avanzados (DEA) en Doctorado en Derechos Humanos y Desarrollo, y candidata a doctora de la Universidad Pablo de Olavide de Sevilla (España). Integrante del Grupo de investigaciones históricas sobre el Estado nacional colombiano (Categoría D de Colciencias), e investigadora en el proyecto "Los caudillos militares colombianos de la segunda generación (1853-1902)”. Correo electrónico: elisamartinpere@gmail.com

Referencia para citar este artículo: Martín Peré, Elisa. "Justicia agraria y conflictos de tierras en Colombia durante la primera mitad del siglo XX. El caso de Santander”. Historia y Espacio 47 (2016): 95-122.

\footnotetext{
* Artículo Tipo 1: de investigación científica según clasificación de Colciencias. El presente artículo es resultado del proyecto de investigación de la tesis de maestría en Historia de la Universidad Industrial de Santander, titulada "Historia del derecho a la tierra en Santander: conflictos de tierras, justicia agraria y parcelaciones en el siglo XX".
} 


\section{Justicia agraria y conflictos de tierras en Colombia durante la primera mitad del siglo XX: el caso de Santander}

Resumen: Este artículo aborda la conflictividad en torno a la tierra en Colombia, a través de la experiencia de la justicia agraria en la primera mitad del siglo XX. Los jueces de tierras, enmarcados en el derecho agrario, son una figura única en la historia de la resolución judicial de conflictos por la tierra en el país. Los informes oficiales, la prensa de la época, revistas agrarias y la documentación judicial rescatada de esta figura, junto con la jurisprudencia de los Tribunales Superiores de Departamento que resolvían las apelaciones interpuestas contra las sentencias de los dos circuitos judiciales de tierras que hubo en Santander, permiten retratar los tipos de conflictividad, lugares y actores, así como intereses de aquellos que pudieron acceder a la justicia agraria durante las décadas de los treinta y los cuarenta, en su corta trayectoria, de apenas seis años. En este periodo, hubo ciertas dificultades para asumir la competencia de los casos, por las resistencias del poder local y departamental. La conflictividad fue de envergadura desde un inicio, y por eso los jueces insistieron en que no podían suprimirse, pese a las continuas peticiones del gobierno nacional al respecto.

Palabras clave: justicia, tierras, derecho agrario, recursos naturales, Santander.

\section{Rural Justice and Land Conflicts in Colombia during the first half of the twentieth century: the case of Santander}

Abstract: This article discusses land conflicts in Colombia, through the experience of agrarian justice, in the first half of the twentieth century. Land judges, framed by the agrarian law, are the only figure in the history of judicial resolution of conflicts over land across the country. Official reports, the news, agricultural reviews and the judicial papers, along with the High Court's jurisprudence, that resolve appeals against the sentences of the two judicial circuits lands in Santander, show as the types of conflicts, places and actors, and interests of people who could use the land justice between the 1930 and 1940, a short trajectory of just six years. During this period, there were some difficulties to assume jurisdiction over cases, because of resistance of local power. The conflict was from the beginning, so the judges insisted that could not be suppressed, despite the repeated requests of the national government in this regard.

Keywords: Justice, Lands, Agrarian Law, natural resources, Santander.

\section{Justiça agrária e conflito pela terra na Colômbia durante a primeira metade do século XX: o caso do Departamento de Santander}

Resumo: Este artigo aborda os conflitos pela terra na Colômbia através da experiência da justiça agrária na primeira metade do século XX. Os juízes da terra, no marco do direito agrário, são uma figura única na história da resolução judicial de conflitos pela terra ao longo desse país. Os relatórios oficiais, a imprensa da época, revistas agrárias e a documentação judiciária resgatada dessa figura, junto com a jurisprudência dos Tribunais Superiores de Departamento, que resolviam as apelações contra as sentenças dos dois circuitos judiciais de terras que houve em Santander, permitem retratar os tipos de conflito, lugares e atores, bem como os interesses daqueles que conseguiram aceder à justiça agrária entre as décadas de 1930 e 1940, em sua corta existência, de apenas seis anos. Durante esse período, houve certas dificuldades para assumir a competência dos casos, pela resistência do poder local e departamental. Os conflitos foram consideráveis, razão pela qual os juízes insistiram em que não podiam ser suprimidos, embora as continuas exigências do governo nacional a esse respeito.

Palavras-chave: justiça, terra, direito agrário, recursos naturais, Santander. 


\section{Introducción}

Son escasas las investigaciones acerca de la conflictividad por la tierra en la primera mitad del siglo XX en Colombia. En el caso particular de la región de Santander, no se conoce hasta ahora ninguna ni se sabe de la existencia de estudios sobre de la figura de los jueces de tierras. De hecho, si bien hubo hasta treinta circuitos judiciales en Colombia entre las décadas de los treinta y los cuarenta del siglo XX, tan solo se sabe de dos investigaciones referentes a este tema en el país ${ }^{1}$.

Este artículo tiene como objetivo contribuir a llenar ese vacío. En las páginas siguientes se muestran los lugares y el tipo de conflictos de tierras que se dieron en el contexto de la labor de los jueces de tierras, así como sus enfoques, la doctrina que fijaron al respecto y las dificultades que encontraron para desarrollar la justicia agraria.

La justicia agraria como medio de resolución de conflictos por la tierra ha tenido como única experiencia en Colombia la prevista en la Ley 200 de 1936 “De régimen de tierras”. Luego, en 1989, se intentó poner en marcha de nuevo, pero tampoco llegó a implementarse en todo el país, y años después se ordenó la suspensión de los tres únicos circuitos judiciales donde operaron. En la actualidad, si bien los llamados Jueces de Restitución de Tierras - en virtud de la Ley 1448 de 2011²-, son los responsables de resolver despojos de tierras acaecidos desde 1991, ellos actúan en un marco diferente al de la justicia agraria, puesto que son jueces especiales creados ad hoc para restituir las tierras en el marco de las consecuencias del conflicto armado en el campo.

De esta manera, los estudios históricos sobre los conflictos de tierras representan un conocimiento que resulta importante para definir la agenda pública en la que se inscriben las políticas de desarrollo agrario del país. Valga recordar que en las negociaciones entre el gobierno y las FARC de

\footnotetext{
1 Elsy Marulanda, “Colonización, hacienda y movilización campesina. El caso de Sumapaz” (Tesis de Maestría en Historia, Universidad Nacional de Colombia, 1988); Adriana de la Cruz y Olga Lucia Pula, "Viotá 1936-1946 y el Juzgado de Tierras de Facatativá” (Tesis de Licenciatura en Historia, Universidad Nacional de Colombia, 1984).

2 La Ley 1448 de 2011 establece un procedimiento para acceder a la restitución y a la formalización de los predios despojados y abandonados forzosamente. Ministerio del Interior, Ley de víctimas y restitución de tierras y decretos reglamentarios (Bogotá: Ministerio del Interior, 2012).
} 
La Habana, el primer punto sobre el agro ha previsto la puesta en marcha de la justicia agraria, que implicaría derivar asuntos que en la actualidad resuelve la jurisdicción civil.

\section{La justicia agraria y los jueces de tierras}

Durante el gobierno liberal de Alfonso López Pumarejo (1934-1938), se impulsó un nuevo modelo de justicia, previsto en la Ley 200 de 1936 “Sobre régimen de tierras”. La justicia agraria y otras medidas, se aplicaron en un contexto económico y social convulso en el que el Estado trataba de modernizar e industrializar el país, así como reubicar en el campo a los miles de campesinos desocupados que se habían empleado como obreros en las obras públicas de las ciudades hasta la crisis mundial de 1929.

En este marco legal, los jueces de tierras asumieron la tarea de resolver pleitos agrarios en un corto periodo de la historia judicial: desde 1938 hasta 1943. Con anterioridad y posteriormente, ha persistido la resolución judicial civil de asuntos de tierras, con leyes que generalmente se han interpretado contra el poseedor a favor del propietario ${ }^{3}$. Algunos de los políticos y magistrados que intervinieron en los debates de la Ley citada, defendieron la justicia agraria como medio para evitar situaciones de favoritismo, confusión y parcialidad, que se generaban desde la justicia civil ordinaria, en relación con los pleitos sobre la propiedad ${ }^{4}$.

Durante mucho tiempo se desconoció la vinculación del derecho agrario con los derechos humanos. Tal como ha sucedido en otras disciplinas jurídicas fuertemente vinculadas a valores, el derecho agrario tuvo sus orígenes en el movimiento humanista ${ }^{5}$. La visión axiológica era necesaria para dar solución a los problemas de la realidad sobre los que se quería incidir. Esta rama jurídica surgió en la primera mitad del siglo XX, expresándose en América con la justicia agraria para superar las dificultades de los sistemas tradicionales de justicia y su formalidad, que impedían la aplicación del derecho material o sustantivo ${ }^{6}$. La segunda etapa de resurgimiento del derecho agrario se dio en la década de los sesenta, con el triunfo de la revolución cubana y las políticas de reforma agraria impulsadas por los gobiernos en virtud de la Carta de Punta del Este con los Estados Unidos (1961-1970), cuya finalidad era detener la expansión del comunismo en América. Salvo estos antecedentes, el derecho agrario ha sido relegado generalmente por el derecho civil.

Este proceso de reconocimiento del derecho agrario e impulso de la justicia agraria se enmarcó en la preocupación internacional por encontrar soluciones a las transformaciones socioeconómicas sufridas en Europa, y en el sector agrario concretamente, tras la Primera Guerra Mundial. Esta situa-

3 Otto Morales, Derecho agrario: lo jurídico y lo social en el mundo rural (Bogotá: Editorial Leyer, 2005), 131.

4 Marco Martínez, Régimen de tierras en Colombia (Bogotá: Ministerio de la Economía Nacional, 1939), Tomo I, 142-143; 386-387 y Tomo II, 109-110.

5 Ricardo Zelendón, "Estado del derecho agrario en el mundo contemporáneo”, Cuaderno Técnico de Desarrollo Rural 29 (2004): 16.

6 Ricardo Zelendón, “Estado del derecho agrario en el mundo contemporáneo”, 16. 
ción se tradujo en la mutación interna de las legislaciones, con acentos de nacionalización de tierras y el surgimiento de la rama del derecho social ${ }^{7}$.

En el derecho interno en Colombia, el reconocimiento expreso de la función social de la propiedad y la impugnación al clásico reconocimiento de la propiedad como derecho natural e individualista, se desarrolló primero a través del pensamiento de Auguste Comte, y después con la teoría jurídica de Duguit. Las facultades de Derecho enseñaban generalmente a autores franceses, por lo que los políticos del momento "bebieron" de su doctrina, como también del "New Deal” de Roosevelt y la economía de mercado de Keynes ${ }^{8}$. Pero en la praxis jurídica, dominaron las teorías clásicas del derecho ${ }^{9}$, en un contexto de crisis mundial del modelo económico liberal.

Si bien desde la Colonia era obligatorio explotar económicamente las tierras adjudicadas, so pena de perderlas ${ }^{10}$, con posterioridad se aprobó normativa republicana que la contradecía. Esta última sostenía la tesis del título de propiedad como requisito suficiente para mantenerla, generando confusión respecto a la normativa a aplicar. Por ello, la reforma constitucional de $1936^{11}$ introdujo expresamente la función social de la propiedad, abriendo la vía a la justicia agraria.

La Constitución de 1886, en vigor hasta 1991, era una declaración de derechos civiles y políticos. Con la reforma de 1936 se incorporó la parte económica y social, si bien los gobiernos deseaban que la aplicación del derecho tributario y los nuevos derechos fuera lenta, para no enemistarse con los grupos sociales dominantes ${ }^{12}$. Así, la Constitución aplicaba el nuevo principio en la última parte del artículo 30, además de reconocer la expropiación sin resarcimiento, y la ley 200 de 1936 imponía a los dueños de la tierra la obligación de laborarla económicamente bajo sanción; el trabajo y no la propiedad otorgaría el derecho a la tenencia de la tierra como solución equitativa, frente a la concepción de la inscripción o el título formal, como requisito para adquirirla.

Pero como se mencionó líneas antes, esta visión no era nueva; algunos congresistas o los jueces de tierras señalaron que la llamada Ley de Tierras suponía un retorno a la legislación española. Como decía el doctor Amaya Ramírez durante el debate del proyecto de ley, éste no tenía nada de

7 Konstantin Katzarov, Teoría de la nacionalización. El Estado y la propiedad (México: Impresora Universitaria, 1963).

8 Carolina Mercado Gabazón, "La influencia de León Duguit en la reforma social de 1936 en Colombia: El sistema jurídico, la función social de la propiedad y la teoría de los servicios públicos” (Tesis de Maestría en Derecho Administrativo, Universidad del Rosario, 2013).

9 Diego López Medina, Teoría Impura del Derecho. Colombia (Bogotá: Editorial Legis, 2004). Se considera la etapa de 1935-1940 como un periodo en el que las nuevas visiones del derecho tendrán cierta acogida por la jurisprudencia, con un énfasis más social, para luego volver a adoptar la doctrina clásica del derecho.

10 Héctor Castañeda, Lecciones de derecho agrario (Bogotá: Doctrina y Ley, 1994).

11 Álvaro Tirado Mejía y Magdalena Velásquez. La reforma constitucional de 1936 (Bogotá: Oveja Negra, 1982); Marco Palacios, De quién es la tierra. Propiedad, politización y protesta campesina en la década de 1930 (México: Fondo de Cultura Económica, 2011); Helena Alviar y Catalina Villegas del Castillo, La función social de la propiedad en las constituciones colombianas (Bogotá: Universidad de Los Andes, 2012); Absalón Machado, El café. De la aparcería al capitalismo (Bogotá: Punta de Lanza, 1977).

12 Otto Morales, Derecho agrario, 225. 
nuevo salvo la extinción de dominio por no explotación, no reconocida formalmente durante la Colonia. El jurista recordaba que la Cédula Real de San Ildefonso de 1780 daba las mismas soluciones equitativas, en función de la efectiva explotación económica del predio. Fue durante la fiebre de las constituciones liberales en el S. XIX, y el interés por alejarse de todo lo que "oliera" a español, en el proceso de conformación de un nuevo Estado, que se ensalzó la inviolabilidad de la propiedad y el reconocimiento de la propiedad privada absoluta y exclusiva, tumbando de un plumazo la otra trayectoria conceptual de la propiedad. La diferencia en las concepciones es aún más obvia en el caso de la regulación del nacimiento de las aguas, consideradas bien común por las leyes españolas, y bien de propiedad privada en el caso francés ${ }^{13}$.

A pesar de ello, la figura de la justicia agraria permitía desde su inclusión en la ley abordar el problema de la tierra de otro modo, puesto que era una justicia tuitiva, o de defensa del que tenía la posición más débil. Así, el juez de tierras debía, en aras de la justicia social, investigar por su cuenta y no resolver únicamente en función de las pruebas y alegatos aportadas por las partes litigantes; pero algunos investigadores consideran que fue una justicia limitada porque los jueces se nombraban por los políticos locales, y por esto se pronunciaban en favor de los propietarios o hacendados de sus localidades ${ }^{14}$. Marco Palacios plantea como limitaciones que el número de jueces de tierras fue ínfimo y que hasta su puesta en marcha, los hacendados tuvieron tiempo de desalojar a aparceros $y$ arrendatarios ${ }^{15}$. Sin embargo, investigaciones como la de Elsy Marulanda ${ }^{16}$ muestran que, aún en estas circunstancias, éstos tuvieron un importante papel mediador de los conflictos por la tierra, tal como ocurrió por ejemplo en el caso de Fusagasugá.

La aplicación de la llamada "ley de tierras" fue muy limitada. Otto Morales señalaba que sólo llegó a aplicarse en 1962, por la paralización deliberada por parte de hacendados y empresarios y porque el legislador no previó los obstáculos procedimentales de la misma ${ }^{17}$. Algunos no vieron peligro alguno en la normativa, como los empresarios y diplomáticos norteamericanos, que no temieron por sus negocios ni siquiera con el proyecto de 1933 , que era más radical ${ }^{18}$. Pero para otros, como los hacendados, representó una molestia por el reconocimiento de tener que pagar las mejoras en caso de lanzamiento del colono, lo cual provocó por un lado el despido previo de arrendatarios y aparceros por

\footnotetext{
13 Hernán Iglesias Benoit, "Reglamento Internacional sobre uso de aguas para regadío en el distrito del Rosario". Ministerio de Economía Nacional. Tierras y Aguas n. 26-27 (1941), 33-80.

14 Manuel Bermúdez, "La construcción histórica de la jurisdicción agraria en Colombia”. Cuaderno Técnico de Desarrollo Rural 32 (2004).

15 Marco Palacios, De quién es la tierra.

16 Elsy Marulanda, "Colonización, hacienda y movilización campesina”.

17 Otto Morales, Derecho agrario, 145.

18 Juan Pablo Ardila Falla, "Reflexiones sobre el imperialismo norteamericano: la política agraria colombiana y la influencia estadounidense en la década de 1930”. Historia Crítica 51 (2013): 185-192.
} 
éstos. Por otro lado, el contenido de la ley incrementó las ocupaciones de tierras por los campesinos, bajo la idea de que ésta les otorgaría gratuitamente la titularidad del terreno ${ }^{19}$.

Igualmente la ley provocó una aceleración del proceso de parcelación como política agraria, utilizada desde 1927 a través del Banco Agrario Hipotecario, aunque también puso fin a ciertos con-

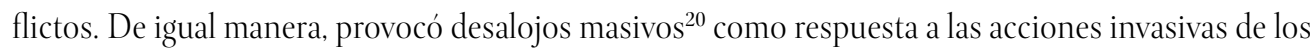
campesinos, pues a partir de 1937 la mayor parte de las parcelaciones efectuadas tuvieron como antecedente invasiones colectivas en zonas de bosque, efectuadas en general por grupos campesinos con sentido comunitario ${ }^{21}$.

Así, como dice A. Machado, la ley 200 fue un intento por modernizar el país y no una ley reformadora. Pero las dificultades técnicas, la falta de recursos económicos para poner en marcha ciertas iniciativas que la ley pretendía impulsar, así como la resistencia de los hacendados a que se aplicara en su totalidad, impidieron que la ley mejorara en ciertos aspectos la problemática de la tierra ${ }^{22}$.

El desarrollo de la nueva jurisdicción de tierras previó la creación, en un principio, de treinta Juzgados, con la idea de que una vez resueltos muchos de los problemas existentes, se redujera el número de juzgados ${ }^{23}$. De esos treinta, había ocho juzgados de tierras que se preveía funcionaran únicamente hasta el 30 de abril de 1939, fecha en la que los municipios adscritos a éstos pasarían a otro circuitos próximos ya existentes. Por tanto, en un principio los legisladores pretendían dar continuidad a la figura de los jueces de tierras, independientemente de reducir su cantidad una vez se evacuara la gran cantidad reconocida de conflictos, y no suprimirlos definitivamente, como sucedió años después.

\section{La experiencia de los jueces de tierras en Santander ${ }^{24}$}

El departamento de Santander, con una extensión de $32.070 \mathrm{Km}^{2}$ y mayoritariamente montañoso (una quinta es parte plana y de poca altura), estaba organizado administrativamente en 73 municipios y el territorio nacional de Contratación. Según el censo de 1938, el 57,3\% de la población de Santander era económicamente activa, con un porcentaje del 81\% dependiente o asalariada, dedicada en su mayoría a la agricultura, pesca, caza, explotación forestal y ganadería ${ }^{25}$.

19 Absalón Machado, El café, 289.

20 Elsy Marulanda, “Colonización, hacienda y movilización campesina”, 335.

21 Adriana de la Cruz y Olga Lucia Pula, “Viotá 1936-1946”, 45-50.

22 Absalón Machado, Ensayos para la historia de la política de tierras en Colombia: de la colonia a la creación del Frente Nacional (Bogotá: Universidad Nacional de Colombia, 2009), 109.

23 “Decreto No. 588 de 1937", Diario Oficial, 8 de abril, 1937, 49-51.

24 Ver mapa de circuitos judiciales de tierras en Santander al final del artículo.

25 Mario Galán, Geografía económica de Colombia. Tomo VIII: Santander (Bucaramanga: Contraloría General de la República, 1947), $3-5$. 
En cuanto a las formas de trabajo y de explotación de la tierra, explica Galán que había varias modalidades: uno era el trabajo a jornal, a cambio de un salario y alimentación o el salario con la comida incluida. Otra modalidad era el trabajo de "brazo vuelto", muy común entre aparceros, cuya remuneración era el alimento y el campesino quedaba obligado a devolver el trabajo hecho por el aparcero en las mismas condiciones. Esta modalidad se debía en parte a su penuria económica, que no les permitía contratar a otros con un salario, pero también por el sentido de solidaridad en algunos casos, entre amistades o familias.

Una tercera forma de trabajo era la aparcería, la más común, consistente en un contrato por el que el propietario daba la tierra al trabajador aparcero para su explotación, bajo unas condiciones diferentes según la región y el tipo de cultivo. El aparcero tenía la obligación de dar al propietario una parte de la cosecha, que podía ser desde la mitad hasta una tercera o cuarta parte, siendo el sistema más utilizado en el cultivo de tabaco y trigo. La aparcería daba escasa rentabilidad, por un lado por la falta de inversión del propietario en la explotación, al no percibir la tierra como factor de producción sino como una renta; por otro lado, debido a la baja densidad de población en algunas zonas del departamento y la escasez de tierra, que provocaba que en ocasiones se aplicara la aparcería en media hectárea, con beneficios muy limitados y dejando a las familias sin ocupación la mayor parte del año.

Por último, estaba el sistema de arrendamiento, propio de las zonas especializadas en cultivo de maíz, o sea en Vélez, Chipatá y Guavatá únicamente. También había pequeños propietarios de microfundio y minifundio, que debido a la poca extensión de tierra que cultivaban, los pocos recursos disponibles, herramientas desfasadas y falta de formación, se encontraban en situación de pobreza permanente, desocupados durante seis meses al año ${ }^{26}$.

Además de este campesinado mayoritariamente dependiente, hacia finales de la década del 30 había unas 25.000 familias de colonos en el sur y Magdalena medio de Santander. Dedicados a la explotación de baldíos por su cuenta y riesgo, vivían en condiciones muy duras. Otros grupos de trabajadores se dedicaban a la explotación petrolera en la zona de Barrancabermeja, donde el monopolio y alza de víveres y arriendos, provocó hacia 1938 un problema social de envergadura ${ }^{27}$. En la década del 40, continuaba la misma precariedad; así por ejemplo, los colonos de la región de "La Colorada" tenían dificultades para conseguir artículos de primera necesidad por la prohibición de la Compañía Tropical de utilizar los autobuses, lo que los obligaba a caminar grandes distancias para obtenerlos, o la negativa a venderles hielo. Había miles de personas diezmadas por las enfermedades y la ausencia de servicios de salud y medios para pagar. Los colonos presentaban sucesivas solicitudes reclamando

26 Francisco Puyana M. "Los campesinos rovirenses carecen de medios adecuados para la explotación de la tierra", Vanguardia Liberal, 10 enero, 1941, 1-2.

27 “De Barranca. Grave problema social”, Vanguardia Liberal, 4 de octubre, 1938, 4. 
caminos, presencia estatal, adjudicaciones de baldíos y ayudas, lamentando las dificultades de la vida en zona selvática ${ }^{28}$.

En la prensa de la época se repiten las escenas de una vida llena de dificultades para los colonos, como los esfuerzos por no ser apremiados por el erario público, que intentaba cobrarles ilegalmente el impuesto predial en concepto de mejoras ${ }^{29}$. Había continuas solicitudes de creación de líneas de créditos agrarios sobre pastos para la zona del Carare, con el fin de superar las situaciones que abocaban al colono a abandonar lo trabajado. Éste descuajaba selva y sembraba pasto, pero no tenía dinero para comprar ganado. Por ello, debía aceptarlo en aumento a precios elevadísimos de los pudientes.

Hacia 1945, un estudio sobre la colonización de la zona mostraba el problema con el que se encontraban los colonos frente a las sanciones por derribo de bosque sin licencia: había más de quinientas personas que no habían podido hacer su roza y siembra al carecer de los recursos para tramitar las solicitudes de los permisos, produciéndose una disminución de la producción de la zona. También planteaban que la falta de vías, de asistencia técnica y ayudas impedía que la colonización fuera exitosa en una población de unos diez mil colonos ${ }^{30}$.

La mayor parte de los bosques inexplotados estaban en zona baldía y su aprovechamiento presentaba tres tendencias: en las zonas ya cultivadas se explotaba para conseguir leña o carbón vegetal, talando el bosque por el sistema de "rocería” que consistía en talar el bosque sin dejar ningún árbol en pie para picar la madera para el uso de la hacienda en hornillos y tejares, y el excedente se vendía para uso doméstico. Ello provocaba un uso irracional del aprovechamiento de los bosques y una fuerte erosión del terreno, situación denunciada permanentemente como se muestra más adelante. Las otras dos tendencias se daban en la explotación maderera de las selvas vírgenes para uso en la industria de la construcción, ebanistería y carpintería, representando ambas un desperdicio de aprovechamiento de aceites, resinas, ceras, fibras colorantes y esencias medicinales, sin respeto por las áreas de reserva forestal o bosques de interés general ${ }^{31}$.

Respecto a la configuración de la producción agraria en esta etapa, fundamentalmente había dos formas: la economía de hacienda orientada al cultivo de café, en torno a la cual se dio principalmente el régimen de aparcería como modo de sujeción de trabajadores y jornaleros, y la economía campesina, basada en el trabajo familiar y centrada en la producción de alimentos. La producción de café era mayoritaria en la década del 30, pues había 45 municipios cafeteros con una producción de 26.956,973 cafetos, 650 despulpadoras y 74 trilladoras, además de otras haciendas dedicadas al

\footnotetext{
28 "Grave problema se presenta a unos colonos", Vanguardia Liberal, 1 de marzo, 1942, 4.

29 "Inquietud entre los colonos por el cobro de impuestos predial sobre mejoras", Vanguardia Liberal, 7 de diciembre, $1940,4$.

30 Pablo Bohórquez, "Estudio sobre la colonización del Opón”. Ministerio de Economía Nacional. Tierras y Aguas, 75 y 76 (marzo y abril de 1945), 133-152.

31 Mario Galán, Geografía económica de Colombia, 414-416.
} 
cultivo de tabaco, caña de azúcar y cacao, entre otros cultivos. Los municipios con mayor número de haciendas cafeteras fueron Lebrija, donde destacaban unas 8 haciendas con cafetales de 300.000 a 90.000 unidades, y Rionegro, segunda zona productora de café del país ${ }^{32}$. En este municipio había unas 20 haciendas de entre 100.000 y 250.000 cafetales, e incluso la hacienda "Berlín”, propiedad de la compañía alemana "Shutte Bunemann and Company", llegó a tener un millón de cafetales; en Bucaramanga hubo más de 70 casas exportadoras e importadoras de diferentes productos ${ }^{33}$.

En cuanto a la jurisdicción de tierras en el departamento, la limitación de dos únicos juzgados, uno en Bucaramanga y el otro finalmente en Vélez ${ }^{34}$ en lugar de San Gil, provocó que muchos casos quedaran sin plantearse ante la instancia judicial. Era muy costoso para los interesados entablar acciones posesorias en lugares tan alejados de algunas zonas del departamento ${ }^{35}$.

En la primera fase de funcionamiento de los jueces de tierras, del 1 de mayo al 30 de octubre de 1937 hubo once procedimientos iniciados ante el juez de Bucaramanga y cuatro ante el Juzgado de Tierras de Vélez. En el contexto nacional los municipios de Tuluá, del Departamento del Valle del Cauca, y Ciénaga, en el Departamento de Magdalena, fueron los que tuvieron mayor número de pleitos $^{36}$. Dos años después los asuntos habían aumentado considerablemente en Santander, en 1939 el juez de tierras de Bucaramanga tenía unos ciento cincuenta y cuatro asuntos, de los que treinta eran juicios posesorios, ciento nueve inspecciones oculares extrajudiciales, tres lanzamientos de hecho y doce inspecciones oculares judiciales. Además, tuvo un total de 151 autos, 7 de ellos sentencias. A su vez, el juez de tierras de Vélez tuvo un volumen de unos 103 asuntos, siendo en su mayoría inspecciones oculares extrajudiciales, además de 30 juicios posesorios, 9 lanzamientos de hecho y un caso de división de gran comunidad ${ }^{37}$.

\footnotetext{
32 Diego Monsalve, Colombia cafetera (Barcelona: Artes Gráficas, 1927), 617.

33 Diego Monsalve, Colombia cafetera, 186-326.

34 “Decreto no. 1229 de 1937 de 30 de junio", Diario Oficial, 23457 de 5 de agosto, 1937. Anexo en Marco A. Martínez E. Régimen de tierras en Colombia. Antecedentes de la ley 200 de 1936 “sobre régimen de tierras" y decretos reglamentarios. (Bogotá: Ministerio de Economía Nacional, 1939, Tomo II). El traslado de la cabecera del juzgado del circuito de tierras de San Gil hacia el sur del departamento, se justificó en el Decreto en que “...los principales problemas de tierras están radicados en las zonas ubicadas dentro de los Municipios de Sucre y Jesús María, en el Departamento de Santander... - - y- ...que dicha ciudad queda muy distante de los municipios donde se contemplan aquellos problemas..." 416.

35 Mario Galán, Geografía económica de Colombia, 225.

36 Adriana de la Cruz y Olga Lucia Pula, “Viotá 1936-194”,186.

37 Dirección Nacional de Estadística, Contraloría General de la República, Anuario General de Estadística, 1939 (Bogotá: Imprenta Nacional, 1940), 364-365.
} 


\section{Casos en la jurisdicción de tierras de Bucaramanga}

El circuito judicial de tierras intervino en varias disputas en el cercano municipio de Rionegro. Allí habían ocurrido algunos de los graves hechos de sangre que mostraban la conflictividad agraria en el departamento y preocupaban a las autoridades

[...] problemas sociales de importancia... Aunque no existen aquí aquellas graves cuestiones originadas por la llamada grande industria o por la acción del capitalismo financiero, generadoras de situaciones permanentes de pugna entre las distintas clases...es lo cierto que basta examinar con sensibilidad democrática y humana el panorama social de Santander para observar la presencia de problemas inquietantes que reclaman urgentes soluciones de justicia...entre esos problemas se destacan con perfiles de gravedad los relacionados con la agricultura. ${ }^{38}$

Es posible que en relación con los lugares conflictivos señalados en el informe, como al nombrar Costa Rica, en Rionegro, se refiera a una de las disputas que giraban en torno a la falta de claridad de linderos y las prácticas de apropiación por parte de algunos que aprovechaban esta situación. Por ejemplo, hubo continuas disputas entre los colonos y un tal Rubén Cristancho, que requirieron de varias inspecciones oculares por el juez de tierras para aclarar quién era el dueño de los terrenos que se discutían entre este señor y sus vecinos. Cristancho fue asesinado por Arturo Prada a las puertas de la Inspección de Policía el 12 de enero de 1942, tras un intento por parte de las autoridades por conciliar a ambas partes. A la salida, Prada, enfurecido y totalmente ido a consecuencia del paludismo que en ocasiones le provocaba la pérdida de conciencia, según él mismo declaró, le asestó varias puñaladas, lleno de ira por la insistencia del otro en querer cobrarle algo que no debía. De las diversas declaraciones se desprende que muchos vecinos consideraban conflictivo al fallecido, quien siempre andaba demandando a los vecinos reclamándoles la propiedad de las mejoras o el pago de las mismas, “...reclamando descumbres y mejoras sin pagar" ampliando linderos para apropiarse de los terrenos colindantes, moviendo mojones o soltando al ganado sobre los predios de los demás ${ }^{39}$.

El intento de conciliación con resultados aciagos trataba de solventar el desacuerdo entre Cristancho, que pedía un mayor porcentaje de cosecha del maíz y arroz que Prada le pagaba, y éste, que decía que no era correcto pues ya había pagado lo acordado. El terreno ocupado por Prada era reivindicado como propio por Cristancho, según título de propiedad aportado, y por eso entendía que debía pagarle la parte completa. Por el contrario, Prada alegaba que si bien el descumbre estaba en

38 "Informe del Ejecutivo de Santander a la Asamblea Departamental" (Santander, 1943), en Archivo Histórico Regional de Santander (AHRS), 29-32.

39 AHRS, Homicidios, caja 82, 16. 
parte de la propiedad de Cristancho, y por ello ya había pagado la cuota correspondiente, la otra parte estaba en un terreno en trámite de sucesión, y por eso no tenía que pagar a Cristancho sobre lo cultivado en ella. Finalmente, el 20 de abril de 1942 la inspección ocular efectuada por el inspector de policía reconocía por la intermediación de los peritos que no había que pagar por esa parte

[...] de ninguna manera al Sr. Rubén Cristancho quien manifestaba ser el propio dueño, pues el descumbre en litigio pertenecía al Sr. Arturo Prada por ser éste quien descumbró esa parcela de terreno que actualmente está explotando económicamente, con consentimiento del Sr Benito Ordoñez S. quien se la había asignado desinteresadamente, sin cobrarle partes de ninguna especie, dadas las circunstancias de que el Sr. Arturo Prada gozaba de general estimación por parte de éste y de los vecinos. ${ }^{40}$

También había tensiones en Vanegas, Rionegro, donde los campesinos bien informados de lo previsto en las leyes, denunciaban que en años pasados el juez de tierras había protegido la propiedad de los baldíos de los colonos y cultivadores con más de diez años de posesión, pero que ahora se veían amenazados de nuevo por un señor. Éste, obrando como si fuera poseedor inscrito, había vendido lotes de baldíos sin exhibir el requerido título de propiedad de al menos 30 años continuos "como demanda la ley", y que si bien podía ser que tuviera mejoras, eso no le permitía enajenar baldíos sin estar titulados ${ }^{41}$.

Hubo disputas que quedaron sin resolver por la vía judicial, por las dudas existentes en torno a la aplicación de la ley. Así, los jueces de tierras desestimaron algunos casos en los que se discutía la propiedad por entender que no era de su competencia. Tal es el caso del juicio ordinario sobre dominio y amparo de posesión de las fundaciones San José de la Laguna y Carrascal, Corregimiento de Galápagos, Rionegro, interpuesto por J. Justiniano Rincón R. contra Pío y Bonifacio Lizarazo ${ }^{42}$.

Algunas intervenciones de los jueces de tierras resolvieron conflictos entre pudientes en los terrenos aledaños a Bucaramanga, como el proceso posesorio interpuesto por los sucesores de David Puyana S.A. contra José Celestino Ordoñez, a propósito de la venta de varias fincas por David Puyana a los señores José Puyana y Gustavo Wolkman. El pleito fue dirimido por el juez de tierras Noriega Rueda, con lo cual podemos deducir que los jueces de tierras no aclararon únicamente cuestiones de tierra entre colonos, o entre hacendados y campesinos, sino que también hicieron uso de esta jurisdicción agraria conocidos terratenientes para aclarar sus cuestiones sobre propiedades ${ }^{43}$.

40 AHRS, Homicidios, Caja 82: 80.

41 "Se venden tierras sin títulos saneados", Vanguardia Liberal, n. 6.950, 29 de enero 1942, 4.

42 Tribunal Superior del Distrito Judicial, “Auto de fecha 16 de septiembre de 1939”, Revista Judicial de Bucaramanga, 1699 (1940) $62-65$.

43 Emilio Arenas. La casa del diablo. Los Puyana: tenencia de tierras y acumulación de capital en Santander (Bucaramanga: Impresores 
En materia de recursos naturales, hubo dos pleitos sobre aguas interpuestos por la Compañía de Aguas de Bucaramanga. Con fecha del 30 de enero de 1841, en el primero de los pleitos, se revocó la sentencia del juez de tierras de juicio posesorio, iniciado por la Compañía del Acueducto de Bucaramanga, absolviendo al doctor Eduardo Rueda Rueda a propósito de las perturbaciones en el uso de unas aguas. Se reclamaba el amparo de la posesión de todas las aguas de la hoya ubicada dentro del predio "Alto de Buenavista", procedentes de la quebrada La Malaña o La Flora, y que el demandado se abstuviera de recabarlas y llevarlas a la finca "Miramanga", en virtud de unos títulos de dominio y posterior permuta de las aguas procedentes de dicha hoya, así como de la Resolución del Ministerio de Economía Nacional por el que la Cía. podía derivar ocho litros de agua por segundo. El Tribunal Superior revocó la sentencia anterior por considerar que las aguas que derivaba el demandado no procedían de las que se surtía el acueducto sino de otras ${ }^{44}$.

En el otro caso, el 28 de abril de 1941 se revocaba igualmente la sentencia por la que el juez de tierras absolvía a cuatro demandados por la Compañía Anónima del Acueducto de Bucaramanga, por lavar arena y cascajo donde dicha empresa captaba el agua para el acueducto de la ciudad y perturbaba o ensuciaba el agua. El Tribunal consideraba que la calidad del agua se dañaba y que prevalecía la utilidad pública que le daba la empresa, frente al uso privado ${ }^{45}$.

El resto de conflictos fueron disputas entre colonos por pequeñas extensiones de tierra, o colonos y pequeños propietarios, donde en ocasiones se nos muestra el proceder arbitrario de las autoridades. En uno de estos casos se denunciaba un despojo producido por el juez y el alcalde, en el juicio posesorio por despojo interpuesto por Francisco Flórez Cáceres contra José Joaquín Vargas, solicitando restitucion material del predio rústico "El Molino” y "La Esperanza” en Altoviento, Fracción Pescadero, Málaga ${ }^{46}$. También hay muestras del uso indebido de la justicia, al denunciar como despojos de tierra ocupaciones con justo título, como en un caso de tenencia de tierra a través de un contrato de arrendamiento formal, en el municipio de Suratá ${ }^{47}$.

\section{Casos del circuito judicial del juez de tierras de Vélez}

El juez de tierras actuó en numerosas ocasiones mediante las inspecciones oculares para determinar quién era el dueño del terreno. Entre las acciones interpuestas por los actores de los pleitos,

\footnotetext{
Colombianos, 1982).

44 Tribunal Superior del Distrito Judicial, “Sentencia de 30 de enero de 1941”, Revista Judicial de Bucaramanga, 1702 (1941) 166-171.

45 Tribunal Superior del Distrito Judicial, “Sentencia de 28 de abril de 1941”, Revista Judicial de Bucaramanga, 1703 (1942) 39-45.

46 Tribunal Superior del Distrito Judicial, “Sentencia de 27 de septiembre de 1939”, Revista Judicial de Bucaramanga, 1699 (1940), $72-77$.

47 Tribunal Superior del Distrito Judicial, “Sentencia de 4 de octubre de 1941”, Revista Judicial de Bucaramanga, 1704 (1942).
} 
las posesorias fueron las más comunes, seguidas de los lanzamientos de hecho por perturbación o despojo, frente a ciertos casos menores de oposición a adjudicaciones de baldíos, o de partición de grandes comunidades. En caso de reincidencia de la ocupación de un predio, la ley preveía la condena de cárcel por sesenta días, como en el caso de la señora Teodomila Hernández, condenada por reincidir en la ocupación del predio "La Agrícola”, en el Corregimiento La Flórez, Bolívar4.

Acudieron al juez de tierras desde los municipios de Jesús María, Sucre, Suaita y Bolívar principalmente, quizás por ser las zonas más próximas pero también donde hubo más conflictos. La mayoría de las sentencias recurridas fueron confirmadas por el Tribunal Superior de San Gil, y por tanto fueron dictadas conforme a derecho. En cuanto a la doctrina citada, tanto el juez de tierras como el tribunal superior aludían a las doctrinas modernas del derecho sobre la función social de la propiedad, el abuso del derecho y el enriquecimiento sin justa causa. Así mismo, el juez de tierras apelaba a lo debatido en el Congreso y el Senado durante la redacción del proyecto de la ley de tierras, para fundamentar sus sentencias, dado el desconocimiento local de las novedades. Veamos algunos ejemplos de la labor de ambas instancias judiciales frente a las tensiones por la tierra en el Sur:

En fecha 11 de septiembre de 1940, el juez de tierras de Vélez E. Téllez, estimó la demanda interpuesta por Jesús Saavedra contra Cetronio Hurtado en juicio posesorio ${ }^{49}$, condenando a éste a cesar en la perturbación de la posesión del demandante, al ocupar una de las cinco hectáreas. El juez hizo uso de la hermenéutica para resolver, aclarando que le correspondía decidir si aceptaba o no el dictamen pericial sobre lo que se discutía, pues tenía la potestad de tomar la decisión de forma independiente, según lo establecido en la justicia agraria. También apeló a lo establecido por la ley para reconocer el pago de las mejoras realizadas sobre el terreno para el que perdió la posesión, apelando a la doctrina del enriquecimiento sin causa, el abuso del derecho y el fraude de ley, criterios señalados por éste en más de veinte sentencias; también citaba la jurisprudencia del Tribunal Superior del Distrito y el de la Corte Suprema de Justicia para reforzar su decisión final ${ }^{50}$.

A su vez, el Tribunal Superior de San Gil motivaba sus sentencias mediante una exhaustiva revisión del contenido de la Ley 200 y las doctrinas más modernas sobre la propiedad, recalcando la idea de que ésta ya no era absoluta e intocable, sino relativa en función del uso que se hiciera. Por ejemplo, el magistrado confirmaba la sentencia del juez de tierras por la que se estimaba una demanda de

48 Archivo del Palacio de Justicia de Vélez (APJV), Libro Copiador de Comunicaciones, 1939:130.

49 Margarita Barrera, Mercedes Castellanos Arias y Myriam Espinoza Aguilar, "Análisis de las leyes agrarias y su aplicación en el departamento de Santander a partir de 1936" (Tesis en Derecho, Universidad Autónoma de Bucaramanga, 1984). Tomo 4. En el Tomo 2 de dicha tesis, aparece un listado titulado "Anexo 8. Negocios tramitados por el juzgado de tierras del circuito de Vélez 1937 a 1943 ( $1^{\circ}$ de mayo) (Ley 200 de 1936)”, pero no se cita la fuente, y contrastando los datos, no coincide toda la información suministrada con fuentes como el Archivo Judicial de Vélez o las revistas judiciales de jurisprudencia consultadas.

50 APJV, Libro Copiador de Sentencias. Año de 1940, no foliado. 
lanzamiento por ocupación de parte del predio denominado “Borrascoso y San Isidro”, ubicado en Lanzáduri, previo pago de las mejoras. En el fallo judicial se aclaraba qué se entendía por "abuso de derecho" y las dos doctrinas al respecto: la objetivista, que planteaba que había abuso cuando se traspasaba el ejercicio ordinario del derecho; y la subjetivista, que expresaba que podía haber abuso aun cuando se estuviera sujeto a la norma ${ }^{51}$ mientras se mostraba el alcance social. En otras palabras, para esta última postura, para que hubiera abuso del derecho, además de querer perjudicar, también se requería que su ejercicio no correspondiera "al fin social que sirvió de móvil al otorgarlo", reforzando la idea de que no había "...derechos absolutos sino relativos al uso que de ellos se haga”2.

Estos nuevos criterios permitían superar la tesis dominante de que el título de propietario era el principal y único elemento a considerar para resolver las dudas sobre la propiedad de un predio, argumentación basada en el Código Civil y el derecho privado. Aplicaban la nueva perspectiva social, que otorgaba el derecho al que trabajaba la tierra, y no a quien la tenía titulada.

Por otro lado, el tribunal aclaraba las competencias de los jueces de tierras respecto a los jueces civiles, y sus diferentes modos de actuar. Recordaba que en virtud de la introducción del principio inquisitivo de la prueba, propio de la rama penal, los nuevos jueces podían llevar cualquier elemento que consideraran pertinente para ilustrar el caso, y tenían la obligación de realizar una inspección ocular previa, para una directa apreciación de los hechos. Ello marcaba la diferencia respecto a los jueces civiles, que se debían ajustar a las pruebas aportadas por las partes. Esta cuestión no era baladí, ya que el juez de tierras debía impulsar el proceso protegiendo al más débil, según los principios del derecho agrario, aportando las pruebas necesarias para aquellos que carecían de recursos para pagar un buen abogado.

Así, en los mismos términos de fundamentación jurídica sobre el nuevo derecho moderno, se hacía prevalecer en una sentencia la posesión material sobre la inscrita en un caso de apropiación de tierra. Uno de los actores había utilizado la artimaña de ampliar linderos de una finca para posteriormente incorporarlos en la inscripción registral. Se trataba de una disputa entre un empresario y tres colonos, por unos terrenos ubicados en una gran propiedad en el municipio de Bolívar ${ }^{53}$. El juez desestimaba el amparo de posesión solicitado por el demandante empresario. Éste había pedido el amparo alegando que los colonos perturbaban su posesión en el predio denominado "Cañabrava”, talando una montaña que él había preservado para la conservación de aguas y para hacer uso de la

51 Para defender esta postura se citaba, entre otros, al jurista francés Louis Josserand (1868-1941).

52 Tribunal Superior del Distrito Judicial de San Gil, “Sentencia de 17 de agosto de 1939”, Revista Judicial de San Gil, 97-98 (1939): 494.

53 Tribunal Superior del Distrito Judicial de San Gil, 24 de abril de 1940, Revista Judicial de San Gil, 106-107 (1940): $330-342$. 
fuerza del agua con la idea de mover la maquinaria de su empresa; también para construir cercas y producir madera para el aserrío.

De la prueba pericial se acreditaba: por un lado, el daño al caudal de aguas era provocado por la tala y desmonte del propio empresario; por otro, frente a la posesión inscrita aportada por éste, la realidad reflejada en la visita ocular era diferente. Esta situación fue a su vez corroborada por las declaraciones de doce personas, entre las que estaba un tal Aureliano Ballén, quien era poseedor de los lotes de los demandados. El señor Ballén presentó un certificado del Registrador de Instrumentos Públicos, por el que se acreditaba que su esposa había sido adjudicataria de dichos terrenos, en su momento baldíos, y que después vendió a los demandados, los Duarte y el señor Herrera.

Así, había una escritura pública de 1936 por la que se constituía una sociedad colectiva de comercio denominada “Londoño López y Compañía” y se transferían los derechos sobre unos terrenos que incluían "los tres desmontes hechos por los Duartes allí, desmontes incluidos en esta alinderación, y las mejoras consistentes en desmontes, sementeras, construcción de un molino de madera para caña de azúcar, construcción de tres casas...". Pero el propio certificado ya señalaba la inseguridad jurídica del negocio: “... no aparece constancia del registro... por medio de la cual ...adquirió.... los derechos... y que por tanto el Registrador se abstiene de certificar sobre quién es el actual poseedor inscrito de los mencionados derechos" 54 .

Así, frente a esta posesión inscrita en parte irregular, la inspección ocular y los declarantes reconocieron que los desmontes y la explotación económica de los colonos, efectuados sobre parte de los terrenos considerados de la finca de unas 400 hectáreas, si bien lindaban con la propiedad de los Londoño, al menos desde 1927 tenían otros poseedores de forma continua. Se aclaraba también que los poseedores actuales eran tanto el señor Herrera, desde hacía cinco años, como los Duarte, desde hacía unos dos años.

Un año después el mismo predio volvía a ser objeto de controversia, en relación con la parte reservada, decían los empresarios, para producción de maderas del aserrío. El juez esta vez sí estimó las pretensiones de lanzamiento del señor Plata, un ocupante de hecho. La sentencia ${ }^{55}$, basándose en la inspección ocular y la mayoría de las declaraciones de los testigos, consideraba acreditado que desde hacía varios años los Londoño mantenían un cultivo de caña de azúcar, trapiche para elaboración de miel y empresa de aserrío. Decía el fallo que si bien no habían tumbado montaña ni realizado actos de dominio, tenían reservada esa zona. Los testigos relataban la posesión continuada de esos terrenos: que al inicio fueron de Teófilo y Emilio Duarte, derribando monte y cultivando terreno, que los

54 Tribunal Superior del Distrito Judicial de San Gil, 24 de abril de 1940 Revista Judicial San Gil, 106-107 (1940): 333.

55 APJV, Libro copiador de Sentencias, año 1940, no foliado. 
heredó Nemesia Duarte, y ésta los transmitió a los señores López Isaza por venta. Después, éstos los transmitieron a los Londoño, quienes para proveer de maderas a su empresa tenían reservada la parte donde derribó árboles Plata.

Otro caso en torno a la explotación de maderas, es el del juicio de lanzamiento por ocupación de hecho interpuesto el 6 de marzo de 1940, por picar leña en una zona del predio denominado "El Bosque”, en el municipio de Suaita ${ }^{56}$. Según la demandante, el predio lo había adquirido la familia de su difunto esposo mediante escritura de compraventa en junio de 1926, para destinarlo a explotación de maderas a modo de reserva forestal, por un lado, y para conservación de aguas por otro. Era la parte alta de una serie de fincas que su esposo y otros herederos recibieron, y que formaban parte de la hacienda "San Joaquín”. Según los testigos, parte del predio en discusión estaba destinado a agricultura, y parte a explotación de maderas para menesteres de la hacienda, afirmando que desde hacía muchos años los dueños pertenecían a la misma familia.

Los peritos observaron que de ocho hectáreas, tres estaban efectivamente destinadas a agricultura y el resto a aprovechamiento de maderas, habiendo un desmonte reciente de unos pocos meses de un cuarto de hectárea. El juez acordó decretar el lanzamiento de los demandados, con las sanciones previstas en la ley y condenando a pagar las costas del juicio. El gasto más elevado era la inspección ocular y las “agencias en derecho”, pues lo demás eran básicamente las cantidades de hojas de papel sellado y portes de correos, así como los desplazamientos. Estas cantidades, que eran muy elevadas -sumaban un 25\% del valor del predio-, impidieron que se plantearan más demandas ante la justicia.

Las áreas de protección forestal que establecían las leyes y los temores generales por la creciente deforestación, merecen un comentario aparte. Los expertos eran conscientes de los problemas de orden social que podía acarrear la protección, también eran conscientes de la incidencia de los campesinos en la destrucción ambiental, debido a la pobreza y abandono en la que se encontraban: "Para defender la zona forestal hay que comenzar por defender al campesino. No es el campesino quien destroza el suelo; es la sociedad la que ha abandonado al campesino, le lanza a quemar el bosque..." ${ }^{57}$. El autor explicaba que la deriva de éstos a las cordilleras se debía a que las tierras cultivables estaban en manos de propietarios, con otros intereses diferentes al social, dedicadas a la especulación y la ganadería extensiva.

Por ello, señalaba este experto en otro estudio, donde analizaba la problemática en Santander, que este problema era económico, de protección, y social, que las herramientas jurídicas implicaban expulsar al campesino de las zonas protectoras “...lo que equivale a condenarlas a una vida de miseria,

56 Margarita Barrera, Mercedes Castellanos Arias y Myriam Espinoza Aguilar, “Análisis de las leyes agrarias”, expediente judicial fotocopiado, Anexo n. 8, 1984.

57 Pedro del Pozo, “Bosques. Iniciación de una política forestal en Colombia”. Tierras y Aguas. 32-36 (1941): 16-34. 
de una miseria mucho mayor que en la que yacen" ${ }^{58}$. A su vez, alertaba de los problemas de orden público que se generarían, preguntándose si las autoridades tenían los medios para enfrentar el problema de la desocupación, respondiendo que no.

Volviendo a los litigios, un tercer caso que muestra que el negocio de maderas era codiciado y motivo de reyertas, además de un peligro para la preservación del agua y por tanto de los bosques, es el del predio de unas 60 hectáreas ubicado en la vereda "Mulatal”, jurisdicción de Chipatá59. Se trataba de la ocupación y perturbación de la posesión mediante la tala y desmonte contra la única quebrada que bañaba el predio. El tribunal confirmaba la sentencia del juez de tierras, que ni siquiera daba lugar al pago de mejoras, puesto que en virtud del artículo 9 de la ley 200, estaba prohibido tanto para propietarios particulares como para cultivadores de baldíos talar madera en las vertientes de agua.

Los recursos maderables eran apetecidos tanto en el ámbito nacional, para consumo doméstico y por las empresas mineras y de ferrocarriles, como en el ámbito internacional, por el negocio de la guerra durante la segunda guerra mundial. Este bien se utilizaba para construir buques mercantes, algunas partes de los aviones y también el carbón de leña comprimido se utilizaba para las máscaras contra gases, así como para producir gasolina ${ }^{60}$. Además, Estados Unidos había perdido el acceso a las primas forestales de Asia, conllevando a un incremento en los precios de la quina, el caucho, las ceras y resinas. Esto provocó una depredación aún mayor del bosque: “....una nube de agentes comerciales, comisionistas, explotadores forestales... se han lanzado sobre los llanos y zonas montañosas del país... a quienes nada importa la conservación de las fuente de riqueza..." ${ }^{21}$.

Otro aspecto a resaltar de la sentencia en apelación antes analizada, es la insistencia en el cambio de criterio respecto a la posesión, con la nueva normativa sobre tierras. El ponente resaltaba la preponderancia de la posesión material sobre la inscrita y la importancia del papel del juez de tierras y la prueba de la inspección ocular, para que éste resolviera en favor del que realmente explotara la posesión. En este caso, el demandante mostraba cómo desde los años veinte la posesión del predio baldío se transmitió; concretamente, pasó por las manos de cinco personas entre negocios de compraventa y una sucesión, en un plazo de seis años - una muestra más de la continua movilidad de la tierra baldía-. Pero no aportó prueba alguna de que la explotara económicamente en esta época. Sin embargo, la inspección ocular y las declaraciones así lo reflejaron, y por ello se estimó la petición del demandante $e^{62}$.

58 Pedro del Pozo, "Bosques. Iniciación de una política forestal en Colombia”, 17.

59 Tribunal Superior del Distrito Judicial de San Gil, “Sentencia de 2 de julio de 1943”, Revista Judicial de San Gil, 138-141, (1943): 243-249.

60 Embajada Británica, “Los productos forestalesen la guerra”, Tierras y Aguas, $65-66$ (1944): 40-42.

61 Pedro del Pozo, "Bosques. Iniciación de una política forestal en Colombia”, 24.

62 APJV, "Diligencia del juez de tierras de 3 de Julio de 1939", legajo suelto. 
Igualmente se constata un caso de despojo de tierras en una hacienda de explotación de maderas en Confines ${ }^{63}$. M. Gómez, viuda de Mejía, demandó a su cuñada Aura M. Chinchilla de Mejía y su hermano por despojo de la finca "La Caldera". La señora explotó económicamente la finca desde 1910 hasta el año 1938, que se trasladó a Oiba por enfermedad y dejó "La Caldera” a cargo de su hijo M. U. Mejía Gómez y su esposa A. Chinchilla. Se cultivaban sementeras de yuca, maíz, caña dulce y plátano, explotaban los montes cortando madera para construcción, y extraían cáscara de encinos para vender a curtidores de pieles, también arrendaban rastrojos potreros. En septiembre de 1939, la señora Chinchilla "despidió" (sic) de manera violenta al esposo y se adueñó de la finca. La dueña, al saber del despojo, se encaminó a Confines donde la echaron de manera violenta Aura y sus hermanos.

Poco después, Aura Chinchilla vendió la finca en octubre de 1939 al señor J. F. Linares, ante notario en Bogotá, y por eso decía no tener nada que ver con la finca. Alegaban que no eran más que meros tenedores, en virtud de contrato con el Sr. Linares. Pero de cuatrocientas fanegadas, sólo seis habían sido cultivadas por los Chinchilla, con lo cual, decía el juez, se demostraba la no explotación del predio. La falta de buena fe quedaba acreditada por el descuido de la finca durante el periodo de tenencia ilegal de Chinchilla, y la violencia empleada contra la anciana M. Gómez. Además, se establecía que no cabía la doctrina del enriquecimiento sin justa causa porque había un contrato de mandamiento de administración, y la posesión violenta y la mala fe excluían el pago de mejoras.

Otra disertación sobre la doctrina francesa, se muestra en la sentencia de fecha 28 de septiembre de 1939, donde el magistrado G. Galvis confirmaba con una aclaración la sentencia del juez de tierras de fecha 28 de marzo del mismo año ${ }^{64}$. En este caso unos vivientes trataron de adquirir vía judicial una propiedad que cuidaban. En marzo de 1938 A. Matéus demandó a Abel y Carlos Abel González para que le restituyeran del despojo de hecho de la posesión de un terreno denominado "La Argentina” ubicado en "Sitio Nuevo” Jesús María, y prestaran caución en caso de oposición de entrega de la finca. En el procedimiento se probó que la demandante y su esposo eran solamente arrendatarios o vivientes, hecho acreditado por un mayor número de testigos de los demandados que de los demandantes. También se demostró con el título de propiedad aportado por los demandados, resultando de la inspección ocular correspondencia entre las ocho hectáreas reclamadas, y las que figuraban en las escrituras aportadas por los González.

63 APJV, "Libro copiador de Sentencias", 1940, sin foliar

64 Tribunal Superior del Distrito Judicial de San Gil, “Aclaración de 28 de marzo de 1939”, Revista Judicial de San Gil, 97 (1939): $523-538$. 
En ocasiones, los abogados tildaban de comunista el alegato de que se perdiera la propiedad por no ser explotada económicamente: en fecha 14 de marzo de 1940 se confirmaba la sentencia del juez de tierras por la que ordenaba a L. Sotomonte a abstenerse de perturbar la posesión de "Santa Rosa" del municipio de Cite y condenaba a pagar el valor de una cerca destruida. Se trataba de un conflicto entre comuneros, en el que uno de los abogados cuestionaba que la no explotación económica del predio fuera motivo de pérdida del predio por ser comuneros, al considerar que no estaba consagrado institucionalmente y que era un principio "de marcado sabor soviético". El abogado contrario recordaba que sí lo preveía la Ley 200 , y que “... tenga o no sabor soviético, ello implica un mandato general..." apelando a que “...él en el ejercicio de esta profesión, necesariamente tiene a diario la oportunidad de apreciar mayormente su importancia y necesidad"65.

A veces los pleitos se debían a la falta de liquidación de bienes en juicios de sucesión, lo cual dejaba a personas de diferentes familias o diversos vínculos ocupando un mismo terreno, como el caso de F. Gaona contra la mujer ${ }^{66}$ de su padre fallecido, y su nueva pareja. En este posesorio, el juez de tierras condenaba a los demandados a abstenerse de perturbar la posesión de un predio en la vereda de "San Lorenzo" en el municipio de San Benito. El Tribunal Superior revocó el fallo, al mostrar la prueba practicada que ambos poseían a la vez y que el demandante en su momento había confesado no tener la posesión del predio ${ }^{67}$.

Otra práctica común, ilegal, era la venta de derechos hereditarios, que como decía el juez de tierras en un pleito de oposición a la adjudicación de un baldío en el municipio de La Paz, no transmitía realmente el bien, “...apenas transmite al comprador los derechos en abstracto, y es solamente el acto de adjudicación en la correspondiente partición, lo que transmite el dominio sobre los bienes herenciales..." ${ }^{68}$. Este fallo judicial repasaba las sentencias más destacadas que fijaban la prevalencia de la posesión material y el modo de prueba para acreditar que un bien era privado y no baldío, como la conocida Sentencia de la Corte Suprema de Justicia, de 15 de abril de 1926. En dicho fallo se establecía, ya antes de la Ley 200, que primaba la posesión material frente a la inscrita, debate provocado como ya hemos dicho por la contradictoria normativa de la época.

De nuevo el Tribunal de San Gil se extendía para apuntalar los nuevos principios y modernas teorías del derecho, impulsadas por la ley 200, en un caso de amparo de posesión en la vereda de Guausa, municipio de Gámbita. Al ser contradictorias las pruebas testificales de demandante y demandado, de dudosa veracidad las del demandante con independencia de las escrituras que aportó,

\footnotetext{
65 Tribunal Superior del Distrito Judicial, “Sentencia de 14 de marzo de 1940”, Revista Judicial de San Gil, 103-105 (1940): 144 66 Las mujeres, principalmente aparecen litigando como "viudas de...", si bien algunas litigan directamente en su nombre. 67 Tribunal Superior de Distrito Judicial de San Gil, “Sentencia 21 de mayo de 1942”, Revista Judicial de San Gil, 127-130 (1942): 320-335.

68 APJV, libro copiador de sentencias de 1940 , sin foliar.
} 
se infirió de la práctica ocular y las declaraciones que realmente se trataba de un caso de comuneros discutiendo sobre un predio comunal. El recurrente planteaba ante el Tribunal que el juez de tierras estaba sometido a la tarifa legal de pruebas y que por tanto no podía “...bajo una supuesta "persuasión racional... desechar un haz probatorio para decidir un negocio" sin mostrar una mejor probanza ${ }^{69}$. El Tribunal confirmaba la sentencia, considerando que el artículo 21 de la Ley de tierras, era una clara manifestación de que el legislador:

[...] quiso reaccionar contra el sistema de la tarifa legal, inflexible y matemática, consecuencia lógica del criterio aún imperante sobre interpretación restrictiva y algebraica del texto [...] Hoy se agita en el mundo jurídico una reacción contra esas prácticas; se quiere acabar con el fetichismo de la ley escrita y [...] extender su radio de interpretación [...] no todo derecho está contenido en la legalidad. ${ }^{70}$

Hay constancia de otros pleitos de tierras ocurridos en Gámbita, sobre particiones de grandes comunidades $^{71}$, como el caso de "El Palmar y Corontujo". Se estimó por el juez de tierras una donde se acreditaba mediante escrituras que desde el año 1879 se había formado una comunidad sobre predios, que con posterioridad se habían producido más de sesenta y cuatro transmisiones, y por tanto la comunidad tenía una antigüedad de más de 30 años, tal como exigía el Código Judicial. También debía acreditarse que el bien tenía un valor superior a los 10.000 pesos, demostrándose en el juicio que éste ascendía a unos 70.000 pesos. Por último, la demanda debía ser interpuesta por más de cincuenta personas, siendo cincuenta y cinco los individuos que solicitaron judicialmente la división de la comunidad, en terrenos ubicados entre Gámbita y Suaita ${ }^{72}$.

En este municipio, la Fábrica de Hilos y Tejidos de San José de Suaita llevaba a cabo varias actividades comerciales en esa época ${ }^{73}$; al parecer también tuvo problemas sobre su propiedad. Al igual que el policía del municipio, la empresa acudió al juez de tierras: en enero de 1940, la gerencia de la “Sociedad Industrial Franco- Belga, Fábricas de San José de Suaita, hilados" escribió al juez a propósito de la Hacienda San José, donde decían tener labores de tejidos e hilados, cultivo de fique a gran escala, potreros para yeguas, ganadería, y parcelas en arrendamiento por determinado tiempo a muchos de sus obreros. Denunciaban que otras personas, sin contrato alguno ni consentimiento, ocupaban potreros y sembraban yuca, arracacha o café. Habían recurrido al inspector de policía para

69 Tribunal Superior de Distrito Judicial de San Gil, “Sentencia de 20 de agosto de 1943”, Revista Judicial de San Gil, 142 (1944): 309.

70 Tribunal Superior de Distrito Judicial de San Gil, “Sentencia de 20 de agosto de 1943”, Revista Judicial de San Gil, 142 (1944): 309-310.

71 Revista Judicial de San Gil, 119-123, (1941): 452-153.

72 APJV, "Libro copiador de autos interlocutorios", 1941, No foliado.

73 Pierre Raymond, Mucha tela de cortar (Bogotá: Planeta, 2008). 
solucionar estas ocupaciones pero éste les dijo que era competencia del juez de tierras. Se quejaban de que ellos no podían pagar los costos del viaje cada vez que ocuparan un terreno. Alegaban que no se trataba de una cuestión de ocupación de baldíos, o de contratos de arrendamiento «... sino sencilla y llanamente del ataque a la propiedad privada por personas que no tienen ningún derecho» ${ }^{74}$.

A continuación, citaban la doctrina del Consejo de Estado sobre la competencia de la policía para intervenir en este tipo de casos y mantener el statu quo. Preguntaban si tenían derecho a un auxilio inmediato de la policia al no haber en la población juez de tierras. El mismo día, 17 de enero, el inspector del entonces Corregimiento de San José, el policía Rafael Rueda Rueda, exponía el mismo caso. Manifestaba que tenía conocimiento por la empresa franco-belga de que algunos arrendatarios y agricultores iban avanzando en los últimos tiempos sobre los terrenos de la empresa sin su consentimiento, situación de al menos veinte años. Ponía el tema en consideración del juez de tierras, por ser el competente y entender que la ley 200 acabaría derogando lo establecido en la Ordenanza $43 / 1933$ al respecto $^{75}$.

La consulta realizada por la inspección de policía de Suaita no era trivial. Se pueden observar las tensiones en torno a la competencia entre la nueva autoridad judicial y algunos alcaldes, e incluso la propia Secretaría de Gobierno, pues estos últimos consideraban que la Ordenanza y la competencia de jueces municipales y la policía debían primar sobre lo establecido en la ley. Así, el 29 de mayo de 1939, el juez de tierras remitía un comunicado al juez municipal de Suaita y a otros municipios -Chima, San Vicente o Simacota, entre otros-, por el que decía tener conocimiento de que se estaban tramitando acciones posesorias y de lanzamientos sobre predios rurales que competían privativamente al juez de tierras. El juez les recordaba el deber de remitirlas, aclarando que la intervención de autoridades de policía, permitido por el artículo 32 de la ley 200, se limitaba a evitar vías de hecho, como la destrucción de cercas o análogos y siempre que la querella hubiera sido presentada en los cinco días siguientes ${ }^{76}$. De nuevo el día 20 de mayo insistía sobre este asunto, reclamando a varios alcaldes que adelantaban demandas de querellas de policía, en virtud de la ordenanza departamental 43/1933, desatendiendo lo establecido en la ley nacional con la obligación de derivárselo a él. ${ }^{77}$

También solicitó al Ministerio jurisprudencia sobre el tema, conocedor de una sentencia del juez de tierras de Facatativá sobre intervenciones de autoridades de policía en juicios de amparo de posesión $^{78}$. Igualmente se lo planteaba al Secretario de Gobierno de Santander ${ }^{79}$, pues de acuerdo con

\footnotetext{
74 APJV, "Libro Anotador de la Correspondencia recibida", 1940, no foliado.

75 APJV, "Libro Anotador de Correspondencia recibida", 1940, sin foliar.

76 APJV, "Libro Copiador de Comunicaciones", 1939: 57-60.

77 APJV, "Libro copiador de comunicaciones", 1939: 64.

78 APJV, "Libro copiador de comunicaciones", 1939, 82.

79 APJV, “Libro copiador de comunicaciones”, 1939, 100-104.
} 
la Ordenanza 43/1933 había tres clases de procedimientos civiles que chocaban con la competencia del juez de tierras en la normativa departamental. El Ministerio de Economía también solicitó información a municipios como Albania o la Aguada Aratoca, Barichara, Betulia, Bolívar, Cabrera, Cite, Confines, Contratación, Sincelada, Curití, Charalá, Chima y a la Secretaria de Gobierno de Bucaramanga. Algunos alcaldes contestaron que no llevaban ningún pleito ${ }^{80}$, como el alcalde de Confines, pero otros como el de Gámbita o el de Charalá, o la Corregiduría de Contratación y la secretaría de gobierno, contestaron que sí llevaban posesorios. La Secretaría apelaba a su competencia, e incluso recibía pleitos de Albania, por petición expresa de la propia Secretaría de que le fueran enviados ${ }^{81}$.

El Ministerio se pronunció al respecto, respondiendo que las autoridades de policía debían mantener el statu quo. Consideraba que los jueces de tierras no podían conocer de las acciones consagradas en ordenanzas departamentales, y que de conformidad con lo dispuesto en el art 52 del decreto 59/1938, las alcaldías debían remitir al juez de tierras los juicios de lanzamiento por ocupación de hecho posteriores a la fecha de marras, pero no las acciones consagradas en las ordenanzas ${ }^{82}$.

Durante los debates del proyecto de la ley 200, el Senador De Chaux ya advertía de que el reconocimiento de la intervención de las autoridades de policía en la ley, provocaría que los poseedores inscritos acudieran a las autoridades de policía y no a los jueces de tierras, lo cual sería perjudicial pues, decía, una jurisdicción de policía es:

[...] por naturaleza arbitraria e irresponsable, cuyas resoluciones no son revisables por los Tribunales Contencioso- Administrativo... y cuya tragedia más honda [la de los campesinos] es causada en nuestro país por la entrega que hace de ellos la ley a la Policía, casi para la totalidad de sus relaciones con los poderes públicos. ${ }^{83}$

A continuación, explicaba que ciertas actuaciones de la policía habían generado o agravado conflictos con los trabajadores agrarios, persiguiendo a los campesinos, cuando con "un poco de sensibilidad social y de tacto” se habrían solucionado los problemas contribuyendo así al orden público.

En cuanto a la existencia de los circuitos judiciales de tierras, a menudo el Ministerio solicitó si era posible suprimir algunos juzgados, a lo que los jueces de tierras respondían negativamente, insistiendo los de Santander en que debían permanecer ambos, por las distancias y para una cómoda y fácil administración de justicia ${ }^{84}$.

80 APJV, "Libro copiador comunicaciones recibidas", 1939, 53.

81 APJV, “Libro copiador de comunicaciones recibidas”, 1939, 61,91, 92 y 93.

82 APJV, "Libro copiador de comunicaciones recibidas", 1939, 94-95.

83 Marco Martínez, Régimen de tierras en Colombia, Tomo 1, 110-112.

84 APJV, “Copiador de comunicaciones”, 1939, 61,69; "Libro copiador de comunicaciones recibidas”, 1939, 209. 
Pero el fin de la experiencia de los jueces de tierras era próximo. Ya a finales de 1937 se intentó acabar con la justicia agraria tras tres meses de funcionamiento, con la excusa de la escasez de casos ${ }^{85}$. En el año 1943, con el argumento de una gran criminalidad en el campo se eliminó definitivamente la justicia agraria, justificándose también por la comisión parlamentaria, por razones de "economía" (se redujeron 145.912 pesos) ${ }^{86}$.Con dicho presupuesto se aprobó el funcionamiento de sesenta juzgados de instrucción criminal en el país. También el mismo año y en virtud de la misma norma, se creó la Guardia Rural, mediante la Ley $4^{\mathrm{a}}$ de 27 de febrero de 1943 sobre seguridad rural y por la cual se dictan otras disposiciones.

Así, en esa nueva etapa se apostó por la seguridad y el incremento del aparato judicial penal, en lugar de la justicia agraria en el campo, como modo de enfrentar los conflictos por la tierra en el país.

\section{Conclusiones}

Hubo una fuerte conflictividad en Santander en torno a la disputa por la tierra en esta etapa. Las autoridades nacionales y departamentales, constataban la grave situación social derivada de las tensiones en torno a la tierra, un mes antes de que se eliminaran los jueces de tierras.

Se asignaron desde el principio dos juzgados sin perspectiva de ser eliminados, a diferencia de otros lugares, lo cual implica que se reconocía por el gobierno al inicio de la experiencia que no eran cuestiones puntuales, sino que había una fuerte conflictividad.

Los jueces de tierras de Santander también mantuvieron la posición de que era necesaria su permanencia, por la cantidad de casos y las distancias, si bien desde los primeros años hubo intentos de supresión de la justicia agraria por parte del gobierno.

El juez de tierras de Bucaramanga intervino en la resolución de conflictos en zonas que también fueron objeto de despojo y tensiones en la década de los noventa y a principios del siglo XXI. Por tanto, hay una continuidad en los lugares afectados por conflictos de tierras. Igualmente, se constata que hubo conflictos entre particulares por otros recursos naturales, como el caso de la compañía de aguas, respecto al uso y origen de las aguas en concesión.

La mayor parte de los casos revisados en el Circuito judicial de Tierras de Vélez, tienen como actores a colonos disputando baldíos. Tierras transmitidas por décadas mediante la compraventa de mejoras entre colonos, o entre empresas madereras y colonos. Los conflictos por recursos naturales como la madera, se acrecentaron en esta etapa por las necesidades derivadas de la segunda guerra mundial, tanto para la propia industria de la guerra, como por la carestía de este recurso para uso

85 Elsy Marulanda, “Colonización, hacienda y movilización campesina”, 237.

86 Es contradictorio apelar a cuestiones de economía cuando se pasa de 22 juzgados de tierras a 60 juzgados criminales, si bien en éstos se suprimía al Oficial escribiente del juzgado de tierras, que cobraba según lo previsto en el Decreto 588/1937, 80 pesos. 
doméstico en Europa, así como por el consumo de los maderables por parte de las industrias mineras y de ferrocarriles en el país.

Asimismo hubo tensiones y resistencias por parte de las autoridades locales y departamentales, para ceder la competencia sobre estos asuntos a los jueces de tierras. También hubo resistencias por parte de algunos juristas en acatar lo establecido por la ley sobre la propiedad, y los jueces y magistrados recalcaron en sus resoluciones el sentido de la ley, con las teorías modernas y la doctrina francesa sobre la función social de la propiedad.

Finalmente, podemos decir que olvidaron el aspecto social en las políticas agrarias, y se dedicaron a potenciar la explotación económica de la tierra. No se proveyó al campesino de medios y alternativas, ni se racionalizó o redistribuyó la tierra según el uso. Ello provocó que, tal como advertían algunos senadores y representantes en los debates de la Ley $200^{87}$ los conflictos por la tierra se mantuvieran bajo nuevas formas de apropiación y disputa, encubiertas, revueltas o invisibilizadas poco después en el contexto de disparatada violencia de la etapa que sucedió, la época de "La Violencia”. Estas tensiones a día de hoy siguen siendo motivo de disputa y confusión, en el contexto del conflicto armado y sus efectos en el campo. 
Mapa 1. Circuitos judiciales de tierras de Santander (1937-1943)

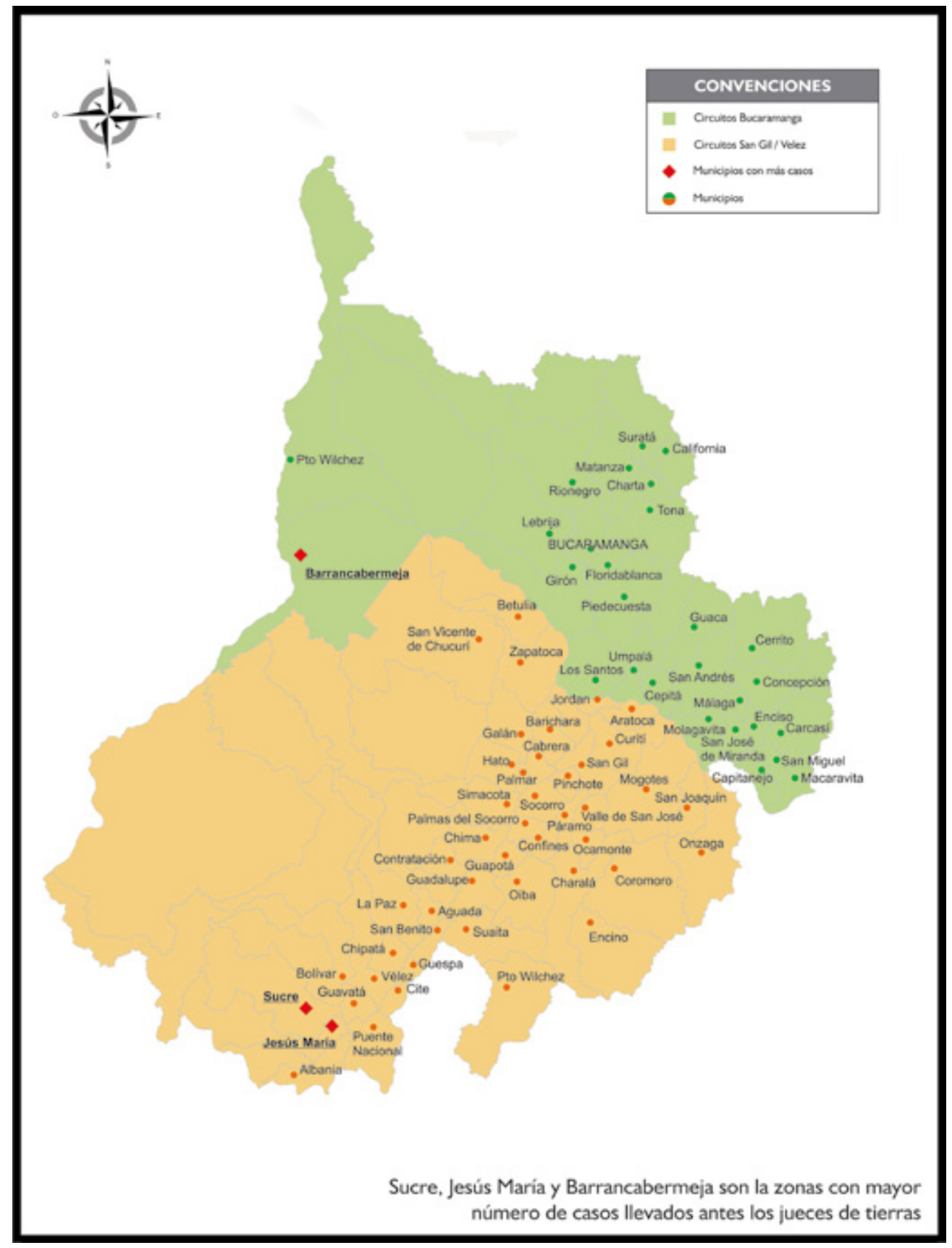

Fuente: Elaboración de la autora a partir de los datos obtenidos en la investigación 


\section{Referencias bibliográficas}

\section{Fuentes primarias /documentales}

"Informe del Ejecutivo de Santander a la Asamblea Departamental" (Santander, 1943), en Archivo Histórico Regional de Santander (AHRS), 29-32.

"Homicidios", AHRS, Homicidios, caja 82, 16.

"Libro Copiador de Comunicaciones", Archivo del Palacio de Justicia de Vélez (APJV), 1939, 57-60, 61, 64, 69, 82, 100-104.

"Libro Copiador de Sentencias", 1940, no foliado.

"Libro Copiador de Sentencias", APJV, 1940, no foliado.

"Libro copiador de autos interlocutorios", APJV, 1941, no foliado.

"Libro Anotador de la Correspondencia recibida”, APJV, 1940, no foliado.

"Libro copiador de comunicaciones recibidas", APJV, 1939, 53, 61,91, 92, 93, 94,95, 209.

\section{Fuentes impresas}

\section{Publicaciones periódicas:}

Contraloría de la República, Anuario General de Estadística, Bogotá, 1939.

Diario Oficial, Santander, 1937.

Revista Tierras y Aguas, Bogotá (1941-1944).

Revista Judicial del Tribunal Superior de Justicia de Bucaramanga, Santander, 1939-1941

Revista Reforma y Justicia Santander (1939,1940, 1942, 1943, 1944).

Vanguardia Liberal. Santander, 1938-1943.

\section{Libros:}

Galán, Mario, Geografía económica de Colombia. Tomo VIII: Santander. Bucaramanga: Contraloría General de la República, 1947.

Martínez, Marco. Régimen de tierras en Colombia. Antecedentes de la ley 200 de 1936 "sobre régimen de tierras" y decretos reglamentarios. Bogotá: Ministerio de la Economía Nacional, 1939. Monsalve, Diego. Colombia cafetera. Barcelona: Ed. Artes Gráficas, 1927.

\section{Bibliografía consultada}

Alviar, Helena y Catalina Villegas del Castillo. La función social de la propiedad en las constituciones colombianas. Bogotá: Universidad Los Andes, 2012.

Ardila Falla, Juan Pablo. "Reflexiones sobre el imperialismo norteamericano: la política agraria colombiana y la influencia estadounidense en la década de 1930”. Historia Crítica 51 (2013): 185-192. DOI: dx.doi.org/10.7440/histcrit51.2013.08

Arenas, Emilio. La casa del diablo. Los puyana: tenencia de tierras y acumulación de capital en Santander. Bucaramanga: Impresores Colombianos, 1982.

Barrera, Margarita, Mercedes Castellanos Arias y Myriam Espinoza Aguilar. “Análisis de las 
leyes agrarias y su aplicación en el departamento de Santander a partir de 1936”. Tesis de pregrado en Derecho, Universidad Autónoma de Bucaramanga, 1984.

Bermúdez, Manuel. "La construcción histórica de la jurisdicción agraria en Colombia”. Cuaderno Técnico de Desarrollo Rural, 32 (2004).

Castañeda, Héctor. Lecciones de derecho agrario. Bogotá: Doctrina y Ley, 1994

Cruz, Adriana de la y Olga Lucia Pula, "Viotá 1936-1946 y el Juzgado de Tierras de Facatativá".

Tesis de Licenciatura en Historia, Universidad Nacional de Colombia, 1984.

Katzarov, Konstantin. Teoría de la nacionalización. El Estado y la propiedad. México: Impresora Universitaria, 1963.

Medina, Diego López. Teoría Impura del Derecho. Colombia. Bogotá: Editorial Legis, 2004.

Machado, Absalón. El café. De la aparcería al capitalismo. Bogotá: Editorial Punta de Lanza, 1977.

Machado, Absalón. Ensayos para la historia de la política de tierras en Colombia. De la colonia a la creación del Frente Nacional (Bogotá: Universidad Nacional de Colombia, 2009).

Marulanda Elsy. "Colonización, hacienda y movilización campesina. El caso de Sumapaz".

Tesis de maestría en Historia, Universidad Nacional de Colombia, 1988.

Mercado Gabazón, Carolina. "La influencia de León Duguit en la reforma social de 1936 en Colombia: El sistema jurídico, la función social de la propiedad y la teoría de los servicios públicos”. Tesis de maestría en Derecho Administrativo, Universidad del Rosario, 2013. Morales, Otto. Derecho agrario: lo jurídico y lo social en el mundo rural. Bogotá: Editorial Leyer, 2005.

Palacios, Marco. De quién es la tierra. Propiedad, politización y protesta campesina en la década de 1930. México: Fondo de Cultura Económica, 2011.

Palacios, Marco. Entre la legitimidad y la violencia. Colombia (1875-1994) Bogotá: Editorial Norma, 1995.

Raymond, Pierre. Mucha tela de cortar (Bogotá: Planeta, 2008).

Tirado Mejía, Álvaro y Magdalena Velásquez. La reforma constitucional de 1936. Bogotá: Ed. Oveja Negra, 1982.

Zelendón, Ricardo. "Estado del derecho agrario en el mundo contemporáneo", Cuaderno Técnico de Desarrollo Rural 29 (2004). 